\title{
Life cycle cost analysis and payback period of lighting retrofit at the University of Malaya
}

\author{
T.M.I. Mahlia, H. Abdul Razak, M.A. Nursahida
}

Lighting system is essential to ensure the comfort, productivity and safety of the occupants in the buildings. Therefore, the lighting system needs to be correctly designed to achieve the desired illumination level while using minimum amount of electricity. Lighting accounts for up to one third of an office building's electricity consumption.

Rational use of electricity within buildings is a very important and relevant subject especially when energy is increasingly becoming more expensive and excessive use of it may cause climate change through high emissions of greenhouse gases [1].

Increase in energy consumption has negative impact on the environment, therefore the policy to use energy efficiently should be proposed. Some of the works related to potential energy savings, cost savings and emission reductions in Malaysia is given by Refs. [2-13].While the paper specifically deal with projected electricity savings, cost-benefit analysis and emission reduction of lighting retrofit for residential buildings in Malaysia in given by Ref. [14]. The cost-benefit is determined as a function of energy savings by retrofitting with more efficient lighting system. The energy savings were calculated based on $25 \%, 50 \%$ and $75 \%$ of potential retrofits of inefficient lighting in residential sector. It was concluded that by adopting this strategy a significant amount of energy and money could be saved. The similar topic about the potential to improve the energy efficiency of lighting systems at Melbourne University [15]. The cost effectiveness of different lighting technology was calculated and the energy consumption of existing $1.2 \mathrm{~m}$ fluorescent lighting fixtures and four energy efficient lighting technology as an alternative was compared. The study found that by installing four lighting technology would result in $13.9 \%, 20.5 \%, 24.4 \%$ and $64.9 \%$, energy savings respectively.

The major electricity used in educational building was lighting system, it consume almost $42 \%$ of total energy. By means of reducing the energy consumption by lighting system already enough to reduce cost. Percentage energy used in educational building is presented in Fig. 1.

The continuing shortfall between electricity demand and supply, the increasing cost of building new power plants and competing 
needs for investment capital are main reasons to encourage

all consumers to choose the energy efficiency technology which give more benefits. University of Malaya also wanted to be one of the green campuses by improving energy efficiency in all aspect.

University of Malaya, or UM, Malaysia's oldest university, is situated on a 309 hectare (750 acre) campus in the southwest of Kuala Lumpur, the capital of Malaysia. The map of the campus showing the building and the road inside the campus is prosecuted in Fig. 2.

There are 447 blocks with total floor are $712,846 \mathrm{~m} 2$ in the campus.

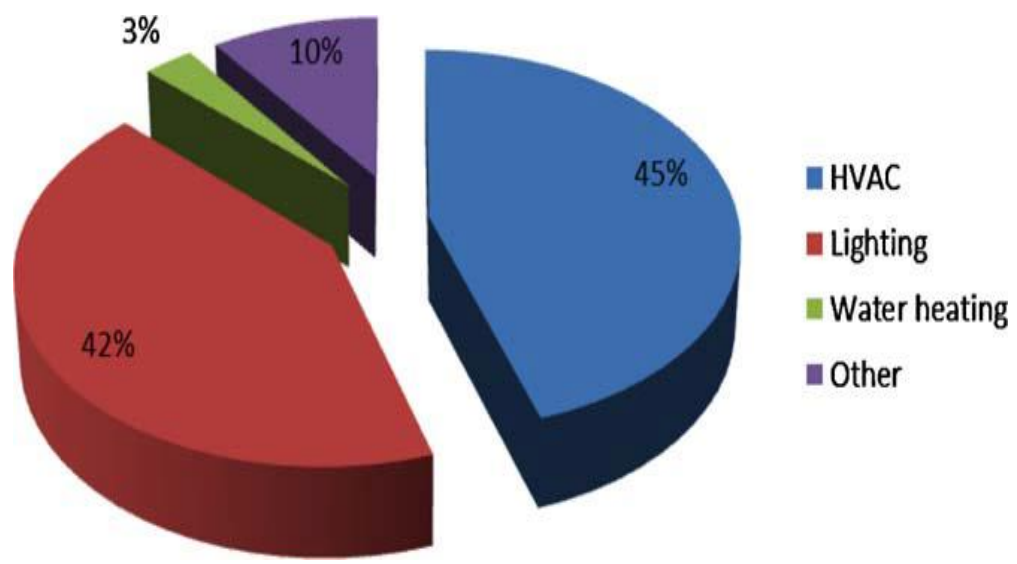

Fig. 1. Percentage energy used in educational building.

This study attempts to calculate potential energy savings and life cycle cost analysis by applying energy efficiency lighting system in the University of Malaya.

\section{Data collection}

Lighting system overview

Many types of lighting system are available in the market but the selection of the lamp depends on the type of task that will be accomplished by the lamp and some properties of the lamp. Incandescent lamps generate light from incandescent filament confined inside the inert environment of the glass bulb. Presently this type of lamp has been slowly phased out due to their low efficacy. The most common type of lamp used today is fluorescent lamp. A fluorescent lamp or fluorescent tube is a gas-discharge lamp that uses electricity to excite mercury vapor. The excited mercury atoms produce short-wave ultraviolet light that then causes a phosphor to fluoresce, producing visible light. A fluorescent lamp converts electrical power into useful light more efficiently than an incandescent lamp. Lower energy cost typically offsets the higher initial cost of 
the lamp [26].

Fluorescent light bulbs come inmany shapes and sizes. They are identified by a standardized coding system that reveals valuable information about operating characteristics and physical dimensions. One key factor is a tube's diameter, and this is given by the number following a ' $T$ ' (which denotes 'tubular'), refers to the tube's diameter, so, for example, a T8 tube would have a diameter of 1 inch [27]. Available energy efficient lighting technology alternative is given in Table 1. Table 2 present few types of lamp and their key performance indices. Various type of lamp has been installed in the University of Malaya, however almost $90 \%$ of the lighting system is fluorescent lamp. The alternative lightings considered in this study are high performance T8 and T5 fluorescent. The relative diameter of popular linear fluorescent lamps is presented in Fig. 3 [27].

This study also includes T5 fluorescent lamp, which is alternative to T8 and T12, an energy efficient option for fluorescent lighting system. The new T5 are $16 \mathrm{~mm}$ wide and $40 \%$ can be smaller than T8 systems. The use of T5 system requires electronic ballast with high efficiency version that can reach a lamp luminous efficacy of more than $100 \mathrm{~lm} / \mathrm{W}$. T5 fluorescent lamp converter with built in ballast is presented in Fig. 4 [27]. T5 systems created by manufacturers compete in the compact fluorescent lighting market. T5 fluorescent lamp is energy efficient that reduces energy consumption of power about $50 \%$ while still providing the same light output as regular fluorescent lights.

Full text available at :

http://www.sciencedirect.com/science/article/pii/S1364032110003618

http://ac.els-cdn.com/S1364032110003618/1-s2.0-S1364032110003618-main.pdf? tid=42364e30-781f-11e3aff7-00000aacb362\&acdnat $=1389156320$ df2b1fb9d6284f42ea53f56bf33b898b 